\title{
The Law of Ideology Interaction and the Strategy of School Ideology Education under the Environment of Opening up
}

\author{
Wei Fu \\ Marxism School, Guangdong University of Foreign Studies, Guangzhou, China \\ Email: scutphdgdufs@hotmail.com
}

How to cite this paper: Fu, W. (2021). The Law of Ideology Interaction and the Strategy of School Ideology Education under the Environment of Opening up. Open Journal of Political Science, 11, 409-418.

https://doi.org/10.4236/ojps.2021.113028

Received: June 7, 2021

Accepted: June 26, 2021

Published: June 29, 2021

Copyright $\odot 2021$ by author(s) and Scientific Research Publishing Inc. This work is licensed under the Creative Commons Attribution International License (CC BY 4.0).

http://creativecommons.org/licenses/by/4.0/

\begin{abstract}
Although ideology is a matter in the field of thought, it is closely related to the real world. The influence of education opening to the outside world on ideology is far-reaching. Different ideologies meet in open areas, and the opening of education promotes the collision and confrontation of different ideologies. In the contest of different ideologies, the interaction between ideologies still presents a certain regularity. Schools are the highland of ideological education. The rapid development of education since the reform and opening up has not only provided knowledge and technical support for national construction and social progress, but also cultivated a large number of middle class, which is different from the revolutionary war period and the early reform and opening up period. Teachers, students studying in school and students about to graduate all become the object of ideological work. The interaction law of ideology plays an important role in this era, which shows that the certain ideology is either accepted or abandoned by more people. Ideological education in schools should shoulder the responsibility of the times, that is, to regulate the movement of ideology, so that what should be followed will be followed better, and what should be abandoned will be abandoned gradually. However, there are some problems in the existing school ideological education mode, which makes it difficult to effectively show this role. This paper further summarizes the existing problems of school ideology, and thinks about how to better carry out school ideological education in the new era and under the condition of education opening to the outside world.
\end{abstract}

\section{Keywords}

Ideology, Education, Interaction, Law, Strategy 


\section{Introduction}

On December 9, 2015, when Xi Jinping presided over the nineteenth meeting of the leading group of the comprehensive deepening reform of the Central Committee, and deliberated the adoption of Several Opinions on Doing A good Job in the Opening up of Education in the New Era, he stressed that education opening to the outside world is an important part of China's reform and opening up. We must serve the overall situation of the whole Party and country and coordinate the two overall situations at home and abroad. We will improve the quality and level of education opening to the outside world. Then, it was pointed out in the ten strategic tasks for the Modernization of Education Deployed in 2035 issued by the CPC Central Committee and the State Council in 2019 that we should create a new pattern of opening up education to the outside world. In the new pattern of education opening to the outside world, cultivating college students' cultural self-confidence is particularly critical (Qian, 2020). Cultural confidence is related to ideology and its education. Ideology is the science of ideas. Ideology also exists objectively. The openness of space and system will change people's ideas. As a collective concept, ideology will gradually change. In an open environment, different ideologies meet, touch and fight here. After a period of wait-and-see, there must be interaction. According to an unpublished survey, there is a negative correlation between age and activity in the process of ideological change. In other words, young people are most active in ideological change in school learning stage. This makes us researchers feel that the ideological interaction in an open environment will bring more thinking to the relevant school teachers. The competition between ideologies caused by the interaction of ideologies will become the starting point of the new imbalance. In the future, to resolve the contradictions caused by the ideological contest, we should solve the problems in the way of ideological education. Under the condition of education opening to the outside world, the traditional ideological education mode with the development of the times is more and more not in line with the needs of the open pattern, which restricts the effectiveness of education opening to the outside world. Education opening to the outside world needs vigorous ideological education strategies. Starting from the discussion of the law of ideological interaction, this paper discusses how to strengthen the ideological education of teachers and students in our country under the premise that the law of ideological interaction plays a role in the process of education opening to the outside world, so as to build a good ideological highland and make more students receiving education in this country feel the influence of Chinese excellent culture, and then, to contribute Chinese wisdom to the world.

\section{The Law of Ideology Interaction}

The first, there is interaction between different ideologies, which is not based on human will. Because there is no completely isolated economy, politics, culture and so on in the world. Different ideologies are different because of the differ- 
ences in economy, politics, culture, science and technology, education, religion, law and nationality. There must be different ideologies in the world. From the macro level, there is no identical ideology, just as there are no identical two leaves. Just as Marx said, in different forms of property and social living conditions, there stands the whole superstructure composed of different emotions, fantasies, ways of thinking and outlook on life. The whole class creates and constitutes all this on the basis of its material conditions and corresponding social relations. Through tradition and education, the individual who bears these feelings and views will think that these feelings and views are the real motivation and starting point of his behavior (Marx \& Engels, 2009).

The second, although the exchange between ideologies is not based on human will, conservative policies will limit the exchange between ideologies, and open policies will promote the exchange between ideologies. The contest between different ideologies is bound to determine the outcome. Generally speaking, ideology, which has gained advantages on the basis of economy, politics and culture, will prevail. Education opening to the outside world is an important way to enhance the international competitiveness of a country's education. In the process of opening to the outside world, a country can shape other countries' understanding and cognition of their own education and national development, and affect the international competitiveness and discourse power of national education. The trade war and the containment of science and technology under unilateralism and conservatism reflect the unbalanced benefits in the process of globalization and the structural contradictions between countries, which constitute a huge challenge to the opening up of education, that is, the ideological war (Jiang, 2020).

The third, from the micro point of view, the ideology that can solve the specific needs of people will be dominant in the specific ideological field of people. Ideology, which can make people feel friendly, will be dominant in the specific field of people's thought. Whether from the micro point of view or from the macro point of view, the ideology that can bring people a sense of honor and belonging will be dominant in people's ideological field. Whether from the micro point of view or the macro point of view, the ideology with foresight, longterm prospects and hope can be dominant in people's ideological field

Finally, Ideological education plays an important role in ideological contest. Ideological educators play a key role in ideological contest. Education has always been regarded as an important way to enhance soft power. Ideological education can promote the cross-border spread of a country's traditional civilization, political concepts and social values, so as to have a long-term and far-reaching soft impact, and obtain more universal international understanding and recognition, which cannot be achieved by hard and solid competition. In recent years, the international practice also shows that ideological education in the process of opening to the outside world has won great initiative for China's foreign policy and expanded the political space in the international community dominated by western discourse (Sun, 2021). 


\section{The Problems of the Existing Ideological Education in Schools}

Ideological education, in the socialist construction has taken an important position and played irreplaceable role. With the gradual improvement of opening up, the interaction between ideologies is becoming stronger and stronger, and the task of Ideological Education in schools will be more and more serious. However, with the continuous progress of the history, the effectiveness of ideological education in contemporary schools has a certain distance from the requirements of society. These problems in the ideological education in schools are like below:

Since the reform and opening up, due to the increase of educational exchanges between China and foreign countries, a large number of students go abroad to study and participate in the work of enterprises under various ownership systems after returning home. Due to the change of ownership, people's work is also diversified, and the way of social information exchange is further changed. All these make us keep up with the trend of the times when we carry out ideological education, and cannot stay at the level of understanding and working in the past. Since the Third Plenary Session of the 16th CPC Central Committee, the non-public economy has been vigorously developed and actively guided. The country relaxes market access and allows non-public capital to enter infrastructure, public utilities and other industries and fields that are not prohibited by laws and regulations. Non-public enterprises enjoy the same treatment as other enterprises in investment and financing, taxation, land use and foreign trade. From this point of view, the changes brought by the development of non-public economy in contemporary Chinese society will not only bring significant changes in the economic field, but also in the political field and social life field.

As for how to carry out ideological education, we can get inspiration from a simple sentence of Mao Zedong, that is, "to make us bigger and bigger and the enemies smaller and smaller". In the New Era, how can the ideological work in schools strengthen our strength? As far as the field of higher education is concerned, its changes are also obvious. In 1999, colleges and universities began to expand their enrollment, and the gross enrollment rate of higher education in China increased rapidly. China's goal of $40 \%$ gross enrollment rate of higher education by 2020 set in the national medium-and-long-term education reform and development plan (2010-2020) has been ahead of schedule and exceeded in 2016 (Yue \& Zhou, 2017). The scale of China's higher education has surpassed that of the United States and ranked first in the world. In other words, China will have a large number of people who have received higher education in the future. This group may be the first in the world either in absolute number or in its proportion to the total population of the country. Chinese society will be in such a situation for a long time. At the same time, the new normal also makes us realize that the ideological work in schools should play an increasingly important role in the overall ideological work. The trend of social development has brought new characteristics to the contemporary ideological work. For the ideological 
education in schools, it is both an opportunity and a challenge.

First of all, social management of individuals. In the past, if we met an unfamiliar person in a city, we would first ask which unit he was from. If we met in a village, we would ask which village or team he was from. It shows that our understanding of an unfamiliar person begins with the understanding of his "unit". It does not mean that a person's name, age, native place, hobbies, family, marriage and other status are not important. Actually, it is very easy to know other information as long as a man's unit was known. Before the reform and opening up, "unit" was the basic unit of national governance. At that time, the ideological work was carried out on the basis of units, and the boundary was very clear and easy to control. Since the reform and opening up, with the development of society, especially more people engaged in non-public sector of the economy or freelance, so the traditional unit system has weakened to a certain extent. The management of individual people has changed from "unit system" to "socialization". Although ideological education can still rely on "units" to carry out effective work, from the national level, the change of people's employment intention caused by the change of social and economic ownership has become a new topic of ideological work.

Second, the field of work has expanded from the real world to cyberspace. The impact of the rapid development of information technology on Chinese society is not only in the economic fields such as online shopping and convenient payment, but also in the social fields such as entertainment and real-time communication. The unparalleled advantages and characteristics of the Internet in information dissemination also have a great impact on people's ideology and play a huge role in the political field. The rise of we media, which relies on the Internet, further strengthens the characteristics of real-time, disorderly, polycentric, and easy to spread. These characteristics not only increase the complexity of social management, but also make the ideological work need to keep up with the pace of the times, quickly broaden the field of work, and be good at learning new skills to deal with the problems that may be encountered in the network.

Third, the door of China's opening up will never be closed. China is a participant, builder, contributor and beneficiary of the current international system. To reform and improve the current international system does not mean to start a new stove, but to promote its development in a more just and reasonable direction (People's Forum, 2016). There also comes a question, that is, in the future reform and opening up, what attitude China should take, what China can provide in the process of international exchanges, and what China needs in international exchanges. After more than 40 years of reform and opening up, it is no exaggeration to say that while we are introducing foreign capital, we have also become a country with a large number of overseas investments. Internationally, our technology and talents are playing an important role. Many of the holders of technology, capital and intellectual resources are people with the background of studying abroad. According to the data of the Ministry of Education, the total number of Chinese students studying abroad increased sharply from 118,500 in 
2005 to 608,400 in 2017 , with an average annual growth rate of $14.6 \%$. China has become the largest source country of international students in the world. In the past, most of the students studied abroad went sent by the government. Now, more and more students studying abroad are at their own expense. In recent years, the proportion of students studying abroad at their own expense has reached more than $90 \%$ (Chen \& Yue, 2020). Therefore, the ideological work in the New Era must take inviting-in and going-out as the ways of working.

\section{Thoughts on the Ideology Education in the New Era}

\subsection{Highly Consistent with the General Political Principles of the Party and the State}

Upholding the Party's leadership, the overall layout of the "five-in-one" and the "four-overall" strategic layout are the important components of the Thought on Socialism with Chinese Characteristics for a New Era. They are also the "methodology" guiding all work (Propaganda Department of the CPC Central Committee, 2018). Xi Jinping's thought on Socialism with Chinese Characteristics for a New Era takes "people's character" as one of the distinct theoretical characteristics. It is to make us clear that in the development of world history, in the contest between socialism with Chinese characteristics and different ideological camps, China has not lost. And, in many cases, it has gradually shown relative advantages. Everything for the people, everything depends on the people, in the contemporary ideological work is still in an important position.

\subsection{Closely Combined with the Characteristics of School}

Ideological work in schools involves two groups, whom are staff and students. From the perspective of ideological work, both teachers and students are involved in the following aspects: First, most of them are in the category of "intellectuals" as we usually call them, and have higher education (Ren \& Zhang, 2013). Both teachers and students, especially professional and technical personnel, have the possibility of frequent career mobility while their life is relatively stable. As a result, they are satisfied with their living conditions; Secondly, because they are the holders and beneficiaries of knowledge or technology, they have more confidence than fear in the future social development; Third, they have a strong learning ability and the ability to accept new things. They are good at summing up their own views and are more willing as well as brave to express their different views; Fourth, they would like to pay close attention to the existing social problems and keep a high degree of vigilance to the social changes. Therefore, the teachers and the students, the object of ideological work in schools, are in the middle of the whole society as to the degree of organization. Although their political mentality varies from person to person, the imprint of the times, combined with the shaping process of learning and career path, has formed a relatively concentrated feature on them, which has become the basis of ideological work in schools. 


\subsection{The Vision of Ideological Work Can Be Further Expanded}

According to a more convincing survey, the basic employment data of college graduates in 2019 shows that $37.7 \%$ of the graduates have been employed and $24.9 \%$ of the graduates go to higher education in China. $4.1 \%$ of the graduates choose to "go abroad". The graduates, who account for nearly 4 tenth of the total number of graduates, choose the options of "free employment", "self-employment", "other flexible employment", "waiting for employment", "no employment, planning to go to higher school", "no employment temporarily", etc. Therefore, from this statistical data, around $40 \%$ of the graduates have the possibility of becoming a "new social class" (Yue, Xia, \& Qiu, 2020). Therefore, ideological work in schools should also consider the potential "new social class" among graduates. This is not only the innovation of ideological work in schools, but also lays a good foundation for the overall ideological work.

As the world enters the information age, the problem of ideology, especially the ideological education in schools, has become more complicated. Therefore, we should study our work objects more deeply and explore the law of ideological education, so as to meet greater challenges. Main battlefield of ideological work in the network era is no longer limited to the real social life and the real office scene, but extended to the virtual space. The network information technology is undoubtedly narrowing the distance between people. Schools have relative advantages in the aspect of network ideology. For example, most of the objects of ideological work are regular users of the network because of the nature of their work or learning. Moreover, the object of ideological work in schools, to a certain extent, still has a strong "unit person" characteristics. Compared with the Internet users in the society, it is relatively easy to organize. There are still challenges in school ideological work. Firstly, the problem to be solved in school ideological work is the problem of concept. In the ideological work of schools, we should pay special attention to prevent missing the opportunity of deep contact and exchange of ideas with the working objects when relying on the network to carry out the work. Secondly, at present, the network provides many platforms for school ideological work, such as website, Wechat, app, etc. Relying on a variety of platforms to carry out school ideological work, we should pay attention to good coordination. When communicating through the working platform provided by the network, we should make overall consideration to the information of multiple channels and platforms. Thirdly, we should also pay attention to the characteristics of the work objects using the Internet, such as what tools they prefer to use for communication, what platforms they pay more attention to, when they usually have time to surf the Internet, and so on. With the help of the network in the ideological work of schools, it has laid a foundation for carrying out the work all the time and in every detail. Moreover, the timetable of school teachers and students are obviously different from those of office workers in general industries. Therefore, it is indispensable to seriously study the preference of school ideological work objects to seek the "greatest common divisor" and 
draw the "maximum concentric circle" in the New Era.

\section{Conclusion}

Under the socialist system, the purpose of ideological education, especially in schools, is to do our best in the process of fighting against the forces contrary to the original intention of socialism.

The opening-up of education is a part of the national policy of opening-up of the whole country. While bringing advantages to the country, it will naturally bring something inconsistent with the socialist system. The opening of education to the outside world has enhanced the communication between domestic teachers and students and foreign teachers and students. This kind of communication is not only the exchange of material and knowledge, but also the exchange of ideas.

In the opening up of education, more private funds become the support and background for students to study abroad, which makes students think that they are using their own or family's financial capital to buy cultural capital. Their state of mind is different from the group of students who were able to study abroad with the public financial support of the country in the past.

Open education makes more young people get the chance of higher education, so they get the status of intellectuals. In other words, open education has created a large number of social members who have become new social strata for the country. This group of social members is different from those in the past. They are not easy to be managed by a collective system because they are floating in every position of the society.

Finally, society has entered the Internet age, creating jobs and job opportunities that are no longer fixed by time and space. In schools, this situation is even more prominent. It seems to make ideological work more difficult, but it also creates opportunities for the expansion of contemporary ideological work in time and space.

As a conclusion, there are some issues to be explained below:

1) The law of interaction between different ideologies is drawn by some material and comes from the schools in the open area. So, it can only describe the interaction of ideologies in open areas. As for the explanatory power of ideological interaction in the sub open areas, data is needed for further evidence.

2) The people's nature in political work is reflected in the ideological work of schools, that is, the concern for all teachers and students.

3) The network has dual effects on the ideological work in schools. In ideological work, we should try to overcome its negative influence.

\section{Acknowledgements}

I would like to express my gratitude to all those who helped me during the writing of this paper. The research related to this paper is supported by the Research Program for "13th Five-Year Plan" of Guangdong Province Education Science 
(Moral Education Special Project 2018JKDY10), “A study of Guangdong Education opening to the outside world and ideological interaction". And, it is also the result of the 2018 teaching research project for Guangdong University of Foreign Studies, the theme of which is Research on the thematic three-dimensional teaching mode of Ideological and political courses in Colleges and universities Research on the thematic and stereoscopic teaching mode of Ideological and political theory course in Universities: Based on the textbook of "Introduction to the Mao Zedong Thought and Theoretical System of Socialism With Chinese Characteristics". Finally, in particular, I would like to express my gratitude to Anonymous Reviewers.

\section{Funding}

This paper is supported by the Research Program for "13th Five-Year Plan" of Guangdong Province Education Science (Moral Education Special Project 2018JKDY10), “A study of Guangdong Education opening to the outside world and ideological interaction". And, it is also the result of the 2018 teaching research project for Guangdong University of Foreign Studies, the theme of which is " $\mathrm{Re}$ search on the thematic and stereoscopic teaching mode of ideological and political theory course in universities: Based on the textbook of Introduction to the Mao Zedong Thought and Theoretical System of Socialism With Chinese Characteristics".

\section{Conflicts of Interest}

The author declares no conflicts of interest regarding the publication of this paper.

\section{References}

Chen, Y.L., \& Yue, C. J. (2020). Trend and Influencing Factors of Chinese University Students' Studying Abroad: 2005-2017. Education Research Monthly, 5, 40-45, 111.

Jiang, K. (2020). China's Higher Education Opening-up: Challenges and Strategic Choices. Journal of National Academy of Education Administration, 12, 28-37.

Marx, K. H., \& Engels, F. V. (2009). Collected Works of Marx and Engels (Volume 2). People's Publishing House, Beijing, p. 498.

People's Forum (2016). What Topics Did Xi Jinping and Obama Meet for 8 Times? http://news.cnr.cn/native/gd/20160403/t20160403 521780518.shtml

Propaganda Department of the CPC Central Committee (2018). Thirty Lectures of Xi Jinping's Thought on Socialism with Chinese Characteristics for a New Era (p. 7). Beijing: Xue Xi Publishing House.

Qian, M. D. (2020). Research on the Cultivation of College Students' Cultural Self-confidence under the New Pattern of Education Opening to the Outside World. Youth and Society, 7, 108-109.

Ren, S. H., \& Zhang, W. (2013). An Analysis of the Growth Track and Political Mentality of Intellectuals Who Choose Jobs Freely. Jianghai Academic Journal, 6, 110-115

Sun, Z. Y. (2021). Four Fundamental Issues in Constructing the Strategy of "China's Education Going Global". Fudan Education Forum, 19, 24-30. 
Yue, C. J., Xia, J., \& Qiu, W. Q. (2020). An Empirical Study on Graduates' Employment: Base on 2019 National Survey. Journal of East China Normal University (Education Science), 4, 1-17. https://doi.org/10.16382/j.cnki.1000-5560.2020.04.001

Yue, C. J., \& Zhou, L. P. (2017). A Trend Study on College Graduates Employment: 20032017. Peking University Education Review, 4, 87-106, 187.

https://doi.org/10.19355/j.cnki.1671-9468.201704005 